\title{
A FINITE ELEMENT ANALYSIS OF STRESS DISTRIBUTION IN ALL ON FOUR SYSTEM USING DIFFERENT FRAMEWORK MATERIALS IN THE MANDIBLE
}

\author{
Seham E. Mohamed*
}

\begin{abstract}
Statement of the problem: The all on four immediate function approach rehabilitating mandibular arch is a successful rout of treatment for resorbed ridges that otherwise would need more invasive approaches, however its outcome depends on the amount of stresses transferred to the surrounding structures. In an attempt to improve mechanical properties of various dental structures, stress and strain analyses under various loading circumstances has become an integral part of researches.
\end{abstract}

This study was aimed to assess the effect of three different framework materials on stress distribution over implants and bone tissue-simulating materials using finite element analyses method.

Materials and methods: Three-dimensional finite element model was created on commercial engineering $\mathrm{CAD} / \mathrm{CAM}$ package. Bone and mucosa were modeled with simplification, while implant system manufacturer data gave sufficient geometrical data to model it exactly. The modeled parts were transferred to ANSYS for assembly, meshing, and analysis. Three types of framework materials were chosen ( $\mathrm{Cr} \mathrm{Co}$, Titanium, and PEEK) to be studied under vertical and lateral loads.

Results: Bone sensitivity to framework material was demonstrated as, increasing framework material elasticity reduces bone stresses. While the total deformation of bone in case of $\mathrm{Cr} \mathrm{Co}$ and Titanium frameworks were equivalent, PEEK material showed the highest bone deformation. All implant complex components also showed increasing stresses and deformation with reducing framework material elasticity. Under the proposed loads, no failure occurred in any component of the model, because Von Mises stress values were found lower than physiological limits.

Conclusion: Within this study limitations, all materials tested were found to be suitable for usage as all on four system framework. Cr Co material showed the best performance, while Titanium was found to be nearly equivalent to it, and PEEK caused the highest stresses and deformations on bone and implant complex.

KEY WORDS: All on four - stress distribution - finite element analysis - framework materials - PEEK.

\footnotetext{
* Lecturer in Removable Prosthodontics Department, Ahram Canadian University.
} 


\section{INTRODUCTION}

Rehabilitation of edentulous arches using implant-supported or implant-retained overdentures is considered a predictable and successful treatment modality. It provides better retention and stability, improving function and esthetics and preserving the residual bone ${ }^{[1-3]}$ Atrophied arches or decreased bone height especially in the mandible, can represent difficulties during treatment with conventional dental implants. In these situations, Prosthodontists often apply increased invasiveness and costly techniques, ${ }^{[4]}$ as bone regeneration, bone grafting, dental nerve trans-positioning or the usage of unconventional implants such as angulated implants..$^{[5,6]}$ For success of implant-retained overdentures, it is influential to control stresses transferred to the bone circumscribing implants through various prosthesis design, type, material, occlusion, and type of attachment. ${ }^{[7]}$

All on four system is a good alternative option because it combines implant tilting and immediate function techniques. ${ }^{[8]}$ To reconstruct chewing capability in the posterior area, masticatory potency might require existing past the most posterior implant. ${ }^{[9]}$ The tilted distal implants have their platforms emerging at the second premolar area, providing enough molar support for the prosthesis masticatory units. ${ }^{[10]}$ Distal tilting of this implants reduces the cantilever length and allows better stress distribution, along with reduction of prosthetic complications, abutment loosening, prosthetic device fractures, or implant failures, which are the inadequacies of cantilever prostheses. ${ }^{[8,11,12]}$

Numerous materials are convenient to construct a prosthesis infrastructure. It is recommended to use metallic alloys exhibiting high tensile strength and elastic modulus sufficient to prevent deformations and" cantilever's fractures. ${ }^{[13]}$ Although cobaltchromium is usually considered the best material as prosthetic framework, its physical properties are not ideal. ${ }^{[14]}$ Titanium alloy (Ti) has corrosion resistance, biocompatibility, economic, and mechanical properties equivalent to auric alloy that makes $\mathrm{Ti}$ a suitable material for construction of prosthesis infrastructure on implants. ${ }^{[15]}$

Poly ether ether ketone (PEEK) is a polymeric material used as prosthetic framework, which is white in color, radiolucent, rigid with great thermal stability. It is non allergic with low plaque affinity. Its Young's modulus and tensile properties are approaching bone, enamel and dentin. PEEK is resistant to hydrolysis, non-toxic and is one of the best biocompatible materials. It has a special chemical structure, which reveals stable chemical and physical properties with low water solubility and absorption. ${ }^{[16-18]}$

To evaluate distribution of stresses in periimplant bone, different methods are used as photoelastic analysis, strain gauge, and finite element analysis. 3D Finite Element Analysis (FEA) is an accurate technique for evaluating the amount and stress distribution pattern in dental structures which has superiority over other techniques. FEA is a reproducible, repeatable and non-invasive technique that could easily simulate any biological condition in pre-, intra-, and postoperative stages. The technique is applicable to linear and nonlinear, along with solid and fluid structural interactions. ${ }^{[19]}$ Also, using finite element analysis method, made it possible to evaluate the stress produced in periimplant bone tissue on a preventive way. ${ }^{[20]}$ Cortical bone properties might differ within cadavers, since this tissue has anisotropic performance producing variable elastic property, according to orientation of the cells and fibers. ${ }^{[21]}$ Thus to standardize in vitro studies and exclude biological variables, resinous materials with elastic modulus nearly resembling the bone tissue are used. ${ }^{[22]}$

\section{AIM}

Using computer simulations (FEA) to investigate clinical circumstances in edentulous mandibles, and recognize the biomechanical performance of three different framework materials utilized in all on four mandibular restorations. 


\section{MATERIALS AND METHODS}

In this current study finite element analysis mimics a clinical circumstance where an edentulous mandible was rehabilitated with an all on four implant system retaining overdenture. Three different materials were used as the overdenture frameworks which were chrome cobalt, titanium and PEEK.

Simplified model (3-dimensional geometry) of edentulous mandible consisting of cortical, cancellous bone and overdenture was created. $[23,24]$ The finite element models' components (prescribed in this in vitro study) as the abutments, screws, implants, overdenture, mucosa, cortical and cancellous bones were created on "Autodesk Inventor” Version 8 (Autodesk Inc., San Rafael, CA, USA) as revealed in (Figure 1). These components were exported as STEP files to be assembled and meshed in ANSYS environment (ANSYS Inc., Canonsburg, PA, USA). The meshing software was ANSYS Workbench version 16 Mesh density was examined and optimized for accuracy and calculation time. Number of nodes and elements of each component were displayed in (Table 1), and meshed components were presented in (Figure 2).

For complete construction of the virtual jaw's model, the bone structure was mirrored from the midline, allowing symmetry between the antimere sides. Bone height was set to be $24 \mathrm{~mm}$, and gingival height of $2 \mathrm{~mm}$. Four implants of $11.5 \mathrm{~mm}$ length and $4.0 \mathrm{~mm}$ diameter. The framework attached to the abutments, presented a height of $5 \mathrm{~mm}$, a $4 \mathrm{~mm}$ width and its length extends to the center of the first molar area on both sides.

The geometric models of implants and components were supplied by the manufacturer (Neobiotech Co., Ltd., Los Angeles, CA, USA) in which two were inserted vertically in the canine region bilaterally, and two inclined implants $\left(17^{\circ}\right.$ distally) were inserted at the second pre-molar region bilaterally. Two straight profile abutments were fastened to the vertical implants, and two angled abutments were fastened to the distally tilted implants. These components were modeled according to manufacturer data. Complete osseointegration was assumed between the used implants and bone, no crater-like defects were present around the implants' necks, along with no gaps in the implant-abutment and abutment framework connections. All utilized materials were presumed to be isotropic, homogenous and linearly elastic and their properties are sorted in (Table 2).

TABLE (1): Mesh density of the model components

\begin{tabular}{|l|c|c|}
\hline & Nodes & Elements \\
\hline Overdenture & 107,050 & 70,814 \\
\hline Bar & 20,496 & 12,779 \\
\hline Mucosa & 14,636 & 2,652 \\
\hline Cortical bone & 132,260 & 81,475 \\
\hline Cancellous bone & 299,817 & 207,147 \\
\hline Implants & 138,145 & 89,763 \\
\hline Abutments & 58,921 & 38,325 \\
\hline 2 long screws & 6,573 & 3,733 \\
\hline 4 Small screws & 17,037 & 10,501 \\
\hline 4 Copings & 11,698 & 6,164 \\
\hline
\end{tabular}

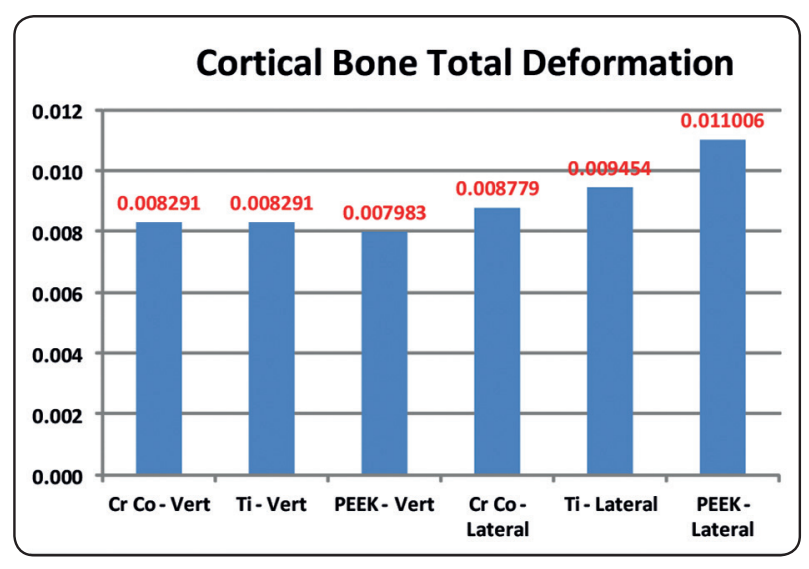

GRAPH (1) Total deformation of cortical bone 
TABLE (2) Materials properties

\begin{tabular}{|l|c|c|}
\cline { 2 - 3 } \multicolumn{1}{l|}{} & $\begin{array}{c}\text { Young's } \\
\text { modules [GPa] }\end{array}$ & Posison's ratio \\
\hline Overdenture (acrylic) & 2.70 & 0.35 \\
\hline Mucosa & 0.01 & 0.40 \\
\hline Bar: $\mathrm{C}_{\mathbf{r}} \mathrm{C}_{\mathbf{0}}$ & 210 & 0.29 \\
\hline Bar: Titanium & 110 & 0.35 \\
\hline Bar: PEEK & 3.76 & 0.38 \\
\hline Implant (Titanium) & 110 & 0.35 \\
\hline Cortical bone & 13.7 & 0.30 \\
\hline Cancellous bone & 1.37 & 0.30 \\
\hline
\end{tabular}

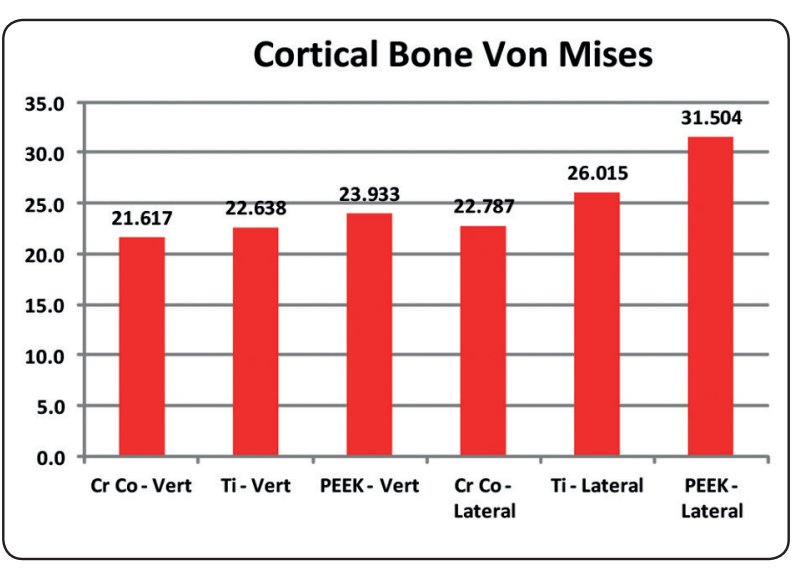

GRAPH (2) Von Mises on cortical bone

For the fixation of the system, the jaw model base was chosen, ensuring restriction of movement on the $\mathrm{Z}$ axis only. Thus, the deformation generated in all directions could be computed easily.

To asses and differentiate the stress distribution on the bone implant interface, two loading situations were simulated using load values close to those of functional bite from patients having the same restoration. The first loading condition is by application of bilateral simultaneous static axial load of $(200 \mathrm{~N})$ on the occlusal surface between the second premolar and the first molar area.
The second loading condition was unilateral horizontal static load of $(90 \mathrm{~N})$ applied on the buccal region of first premolar. Thus, each framework material was tested under two loading conditions.

Linear static analysis and solid modeling were performed on a personal computer Intel Core i7, processor 2.4 GHz., 6.0 GB. RAM. The model was verified against similar studies and showed good matched results. ${ }^{[23,24]}$ The outcomes of the mathematical solutions were transformed into visual outcomes characterized by degrees of color, grading between red and blue, with the red color displaying the highest stress values. The color gradient table was standardized; accordingly, the outcome colors in all the compared situations presented similar stress quantities. The outcomes of the simulations were assessed in terms of von Mises equivalent stress levels at the bone-implant interface.

\section{RESULTS}

As each finite element analysis produces tons of colored distributions for deformations and stresses, in this present study total deformation and Von Mises stress is presented for each constituent of the model. Under the proposed loads, no failure happened in any constituent of the model, and Von Mises stress values were found to be below the normal physiological limits.

Demonstrates Von Mises stress distribution under bilateral vertical load application of $200 \mathrm{~N}$ on occlusal surface of the overdenture between second premolar and first molar area. It was noticed that the stress distribution and deformations did not change with changing the framework material, while the values changed from material to the other.

Under vertical loading, overdenture deformed about $10 \%$ more with PEEK compared to $\mathrm{Cr} \mathrm{Co}$ and $\mathrm{Ti}$, which showed equivalent values. This percent increased to $30 \%$ under lateral load of $90 \mathrm{~N}$, and the gap increased between $\mathrm{Cr}$ Co and $\mathrm{Ti}$ showing slight advantage with $\mathrm{Cr}$ Co framework. Whatever, 
the loading condition was, the framework showed the same behavior as the overdenture. Deformation increased with changing framework material from $\mathrm{Cr}$ Co (least deformation) followed by $\mathrm{Ti}$ and the highest deformation was recorded with PEEK, for all other prosthesis components.

From Von Mises stress point of view, overdenture stress is not sensitive to framework material, while all other constituents of the prosthesis received increasing stresses by changing framework materials from the least produced by $\mathrm{Cr}$ Co followed by $\mathrm{Ti}$ and the highest by PEEK. The Von Mises stress values on the framework itself was found to be the highest in $\mathrm{Cr} \mathrm{Co}$ and less in Ti framework and the least in PEEK.

Under vertical loading, bone and mucosa showed nearly the same deformation behavior with $\mathrm{Cr} \mathrm{Co}$ and $\mathrm{Ti}$ bars, with slight difference recorded on mucosal deformation indicating superiority of $\mathrm{Cr}$ Co framework as shown in (Graph 1) and (Graph 2).

While PEEK framework showed slight less deformation ( of 5\%) on bone and higher deformation on mucosa (about 60\%). The lateral load showed increasing deformation with different framework materials with the least deformation recorded with $\mathrm{Cr} \mathrm{Co}$ then $\mathrm{Ti}$ and the highest deformation was recorded with PEEK. Although Von Mises stress difference percentage between $\mathrm{Cr}$ Co and PEEK may reach $90 \%$ on mucosa, all values were within acceptable physiological limits.

\section{DISCUSSION}

In this study, it was aimed to assess stress figures induced at bone-implant interface using three different framework materials. To guarantee that the results quality would not be compromised owing to the complexity of the model's geometry, it was necessary to divide the structure into a finite number of elements with $10 \%$ convergence.

The FEA has been revealed to be a convenient technique to analyze complex or inconvenient systems that are difficult to standardize throughout in vitro and in vivo studies. ${ }^{[19]}$ The validity of the outcomes depends on the accuracy with which the geometry, material properties, interface situation, support, and loading are in agreement with physical reality. Thus, the real model and the interrelationship between its various components were first evaluated, then the analysis of the discretization of the numeric model with actual geometries and loading type of its working mode was performed.

In vivo studies showed the amounts of occlusal masticatory stresses to be nearly $220 \mathrm{~N}$ in the posterior area. ${ }^{[8,25,26]}$ That's why, a $200 \mathrm{~N}$ load was used to simulate that observed in vivo conditions. Furthermore, the models were regarded to be linearly elastic, thus the magnitude of the load was not as critical.

It is a necessity to perform more investigations with a long-term reliability limit of all on four concept by conducting further clinical-based studies. ${ }^{[27]}$ Although, the stress conjured at the tilted implants surrounding bone is questionable. ${ }^{[28]}$ Results showed that there is reduced stress and bending in the distal implant tilt of $15^{\circ}$ and $30^{\circ}$, where an obvious reduction in the tilt was found. ${ }^{[28]}$ That's why the distal implant tilt chosen in this study was $17^{\circ}$ and it showed good results in reducing bone and implant body stresses.

It was suggested that the prosthetic materials utilized in all-on-four implant-retained device are a significant factor altering stress/strains found in implants and peri-implant bone. In this issue, as some authors ${ }^{[29,30]}$ suggest a metal framework due to its hard structure, other authors ${ }^{[31,32]}$ prefer full-acrylic resin prostheses and recommend utilizing this structure for prolonged periods.

Stress is increased in prosthetic materials with high rigidity and endurance. Although, due to high elastic modulus values of such materials, breakage or mechanical complications as bending and deformations are lower. ${ }^{[33]}$ While implant 
failures were observed with non-metal reinforced restorations. ${ }^{[34]}$ Other authors, ${ }^{[10,35]}$ who have used acrylic resin dentures have reported high survival rates and more preference.

Mechanical problems occurred to the bar-retained acrylic superstructures could be resolved more cheaply than those occurred to other more costly materials. ${ }^{[36-38]}$ This conflict in studies' findings is why the three framework materials $(\mathrm{Cr}$ Co, Ti, PEEK) where chosen to study their induced stresses on the implants and bone. Another reason for choosing PEEK framework, was its elimination of the grayish appearance of the metal frameworks, providing a metal-free esthetic outcome. ${ }^{[39]}$

Many authors ${ }^{[28,40]}$ reported that maximum von Mises stress levels were observed to be decreased than the fracture limit of the materials utilized as bone and titanium which is agreeable with the observations found in this present study.

A study ${ }^{[41]}$ found that stress conjured in all components of the system were not influenced significantly by the framework's material. On the contrary in this present study it was observed that PEEK framework showed higher deformation and less stresses compared to $\mathrm{Cr} \mathrm{Co}$ and $\mathrm{Ti}$, because of rapid increase in stress in relation to small strains corresponding to the viscoelastic performance of PEEK, in which it absorbs more energy from applied load allowing less favorable load distribution. This observation was in agreement with what was observed in former studies. [42-43] Thus, PEEK material increased total deformation on all components of the model except cortical and spongy bone.

\section{CONCLUSIONS}

Within the limitations of this in-vitro study it may be concluded that, all the materials tested are suitable for usage as all on four framework material. CrCo showed the best performance, while Titanium is nearly equivalent to it, and PEEK induced the highest stresses and deformations on bone and implant complex.

More rigid framework materials are capable to distribute the loads on the supporting structures better than less rigid materials. However, less rigid materials may help in absorbing more energy from applied load, undergoing more deformation and distributing the applied load non-uniformly.

\section{Ethical approval}

This research doesn't require ethical approval and followed the Helsinki declaration. The author declares that there is no conflict of interest.

\section{REFERENCES}

1. Amaral C. F., Gomes R. S., Garcia R. C. M.and DelBel-Gury A. A. Stress distribution of single-implant retained overdenture reinforced with a framework: A finite element analysis study. Journal of Prosthetic Dentistry. 2018;19(5):791-796.

2. Kutkut A., Bertoli E., Frazer R., Pinto-Sinai G., Fuentealba-Hidalgo R.and Studts J. A systematic review of studies comparing conventional complete denture and implant retained overdenture. Journal of Prosthodontics Research. 2018;62(1):1-9.

3. Thomason J. M., Feine J., Exley C., Moynihan P., Muller F., Naert I., et al. Mandibular two implant-supported overdentures as the first choice standard of care for edentulous patients. The York Consensus Statment. British Dental Journal. 2009;207(4):185-196.

4. Ravidà A., Barootchi S., Askar H., Suárez-López del Amo F., Tavelli L.and Wang H. L. Long-term effectiveness of extra-short $(<6 \mathrm{~mm})$ dental implants: A systematic review. International Journal of Oral \& Maxillofacial Implants. 2019;34(1):68-84.

5. Fabris V., Manfro R., Reginato V.and Bacchi A. Rehabilitation of a severely resorbed posterior mandible with 4-mm extra-short implants and guided bone regeneration: Case report with 3-year follow-up. International Journal of Oral \& Maxillofacial Implants. 2018;33(5):e147-e150.

6. Bordin D., Bergamo E.T. P., Bonfante E. A., Fardin V. P.and Coelho P. G. Influence of platform diameter in the reliability and failure mode of extra-short dental implants. 
Journal of Mechanical Behaviour \& Biomedical Materials. 2018;77:470-474.

7. Chun H. J., Park D. N., Han C. H., Heo S. J., Heo M. S.and Koak J. Y. Stress distributions in maxillary bone surrounding overdenture implants with different overdenture attachments. Journal of Oral Rehabilitation. 2005;32(3):193205.

8. Malo p., Rangert B.and Nobre M. "All on four" immediate-function concept with Branemark System implants for completely edentulous mandibles: a retrospective clinical study. Clinical Implant Dental Related Research. 2003;5(1):2-9.

9. Shackleton J. L., Carr L., Slabbert J. C.and Becker P. J. Survival of fixed implant-supported prostheses related to cantilever lengths. Journal of Prosthetic Dentistry. 1994;71(1):23-26.

10. Malo p., Rangert B.and Nobre M. All on four immediatefunction concept with Branemark System implants for completely edentulous maxillae: a 1- year retrospective clinical study. Clinical Implant Dental Related Research. 2005;7(1):S88-S94.

11. Krekmanov L. Placement of posterior mandibular and maxillary implants in patients with sever bone deficiency: a clinical report of procedure. International Journal of Oral \& Maxillofacial Implants. 2000;15(5):722-730.

12. Hassine M. B. H., Bucci P., Gasparro R., Lauro A. E. D.and Sammartino G. Safe approach in "All-on-four" technique: A case report. Annali di Stomatologia. 2014;5(4):142-145.

13. Gonzalez. J. The evolution of dental materials for hybrid prosthesis. Open Dental Journal. 2014;16(8):85-94.

14. Wiesli M. G. and Ozcan M. High-performance polymers and their potential application as medical and oral implant materials: a Review. Implant Dentistry. 2015;24(4):448457.

15. Ferreira M. B., Barão V. A., Faverani L. P., Hipólito A. C.and Assunção W. G. The role of superstructure material on the stress distribution in mandibular full-arch implant-supported fixed dentures. A CT-based 3D-FEA. Material Science \& Engineering C. Materials Biological Applications. 2014;35:92-99.

16. Monich P. R., Berti F. V., Porto L. M., Henriques B., de Oliveira A. P. N., Fredel M. C., et al. Physicochemical and biological assessment of PEEK composites embedding natural amorphous silica fibers for biomedical applica- tions. Material Science and Engineering: Clinical Material and Biological Applications. 2017;79(1):354-362.

17. Zoidis P., Papathanasiou I.and Polyzois G. The Use of a modified poly ether ether ketone (PEEK) as an alternative framework material for removable dental prostheses. A clinical report. Journal of Prosthodontics. 2016;25(7):580-584.

18. Liebermann A., Wimmer T., Schmidlin P. R., Scherer H., Loffler P., Roos M., et al. Physicomechanical characterization of polyetheretherketone and current esthetic dental CAD $\backslash C A M$ polymers after aging in different storage media. Journal of Prosthetic Dentistry. 2016;115(3):321-328.

19. Mohammed S. D.and Desai H. Basic concepts of finite element analysis and its applications in dentistry: An overview. Journal of Oral Hygiene \& Health. 2014;2(5):156-166.

20. Carneiro B. A., de Brito R. B. Jr.and França F. M. Finite element analysis of provisional structures of implant-supported complete prostheses. Journal of Oral Implantology. 2014;40(2):161-168.

21. Peterson J.and Dechow. P. C. Material properties of the human cranial vault and zygoma. The Anatomical Record Part A. Discoveries in Molecular Cellular and Evolutionary Biology. 2003;274(1):785-797.

22. Moretti Neto R. T., Hiramatsu D. A., Suedam V., Conti P. C. R.and Rubo J. H. Validation of an experimental polyurethane model for biomechanical studies on implant-supported prosthesis - Compression tests. Journal of Applied Oral Science. 2011;19(1):47-51.

23. El-Anwar M. I., Yousief S. A., Soliman T. A., Saleh M. M.and Omar W. S. A Finite element study on stresses distribution of two different attachment designs under implant supported overdenture. The Saudi Dental Journal. 2015;27(4):201-207.

24. El-Anwar M. I., El-Taftazany E. A., Hamed H. A.and Abd-ElHay M. A. Influence of Number of Implants and Attachment Type on Stress Distribution in Mandibular Implant-Retained Overdentures: Finite Element Analysis. Open Access Maced Journal of Medical Science. 2017;5(2):244-249.

25. Kao H. C., Chung W. N., Chen F. C., Hsu M. L.and Chang K. D. Finite element analysis of different superstructure materials in a single distal implant restoration. Journal of Dental Science. 2008;3(3):140-149.

26. Morneburg T.and Pröschel P.A. Measurement of masticatory forces and implant loads: A methodologic clinical study. International Journal of Prosthodontics. 2002;15(1):20-27. 
27. Durkan R., Oyar P.and Deste G. Maxillary and mandibular all-on-four implant designs: A review. . Nigerian Journal of Clinical Practice. 2019;22(8):1033-1040.

28. Sannino. G. All on 4 concept: A 3- dimension finite element analysis. Journal of Oral Implantology. 2015; 41(2):163-171.

29. Tealdo T., Bevilacqua M., Menini M., Pera F., Ravera G., Drago C., et al. Immediate versus delayed loading of dental implants in edentulous maxillae: a 36 month prospective study. International Journal of Prosthodontics. 2011;24(4):294-302.

30. Malo' P., Nobre M. A., Petersson U.and Wigren S. A pilot study of complete edentulous rehabilitation with immediate function using a new implant design: Case series. Clinical Implant Dentistry and Related Research. 2006;8(4):223-232.

31. Butura C. C., Galindo D. F.and Jensen O. T. Mandibular all-on-four therapy using angled implants: A three-year clinical study of 857 implants in 219 jaws. Dental Clinical North America. 2011;55(4):795-811.

32. Crespi R., Vinci R., Capparé P., Romanos G. E.and Gherlone E. A clinical study of edentulous patients rehabilitated according to the all on four immediate function protocol. International Journal of Oral \& Maxillofacial Implants. 2012;27(2):428-434.

33. Bhering C. L., Mesquita M. F., Kemmoku D. T., Noritomi P. Y., Consani R. L.and Barão V. A. Comparison between all-on-four and all-on-six treatment concepts and framework material on stress distribution in atrophic maxilla: A prototyping guided 3D-FEA study. Material Science \& Engineering C. Materials Biological Applications. 2016;69:715-725.

34. Grunder. U. Immediate functional loading of immediate implants in edentulous arches: Two-year results. International Journal of Periododontics \& restorative Dentistry. 2002;21(6):545-551.

35. Soto-Peñaloza D., Zaragozí-Alonso R., Peñarrocha-Diago M. A.and Peñarrocha-Diago M. The all-on-four treatment concept: Systematic review. . Journal of Clinical \& Experimental Dentistry. 2017;9(3):e474-e488.

36. Timmerman R., Stoker G. T., Wismeijer D., Oosterveld P., Vermeeren J. I. J. F.and Waas M. A. J. V. An eight-year follow-up to a randomized clinical trial of participant satisfaction with three types of mandibular implant-retained overdentures. Journal of Dental Research. 2004;83(8):630-633.

37. Stoumpis C.and Kohal R. J. To splint or not to splint oral implants in the implant-supported overdenture therapy? A systematic literature review. Journal of Oral Rehabilitation. 2011;38(11):857-869.

38. Ayna M., Gulses A.and Acil Y. A comparative study on 7-year results of "All-on-FourTM" immediate-function concept for completely edentulous mandibles: Metal-ceramic vs. bar-retained superstructures. Odontology. 2018;106:73-82.

39. Zoidis P., Bakiri E.and Polyzois G. Using modified polyetheretherketone (PEEK) as an alternative material for endocrown restorations: a short-term clinical report. Journal of Prosthetic Dentistry. 2017;117(3):335-339.

40. Caglar A., Aydin C., Ozen J., Yilmaz C.and Korkmaz T. Effects of mesiodistal inclination of implants on stress distribution in implant supported fixed prostheses. International Journal of Oral \& Maxillofacial Implants. 2006;21(1):36-44.

41. Tribst J. P. M., de Morais D. C., Alonso A. A., Dal Piva A. M. O.and Borges A. L. S. Comparative three-dimensional finite element analysis of implant-supported fixed complete arch mandibular prostheses in two materials. Journal of Indian Prosthodontic Socity. 2017;17(3):255-260.

42. El-Qoubaa Z.and Othman R. Tensile Behavior of Polyetheretherketone Over a Wide Range of Strain Rates. International Journal of Polymer Science. 2015;2015:1-9.

43. Chen X., Mao B., Zhu Z., Yu J., Lu Y., Zhang Q., et al. A three-dimensional finite element analysis of mechanical function for 4 removable partial denture designs with 3 framework materials: CoCr, Ti-6Al-4V alloy and PEEK. Scientific Reports. 2019;9(1):1-10. 